TI 2011-087/3

Tinbergen Institute Discussion Paper

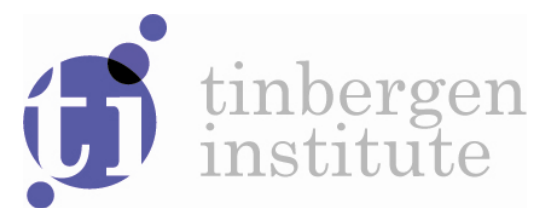

\title{
A Flexible Test for Present Bias and Time Preferences using Land-Lease Contract
}

Pieter A. Gautier ${ }^{\dagger}$

Aico van Vuuren ${ }^{\ddagger}$

† VU University Amsterdam, Tinbergen Institute, and CEPR;

‡ VU University Amsterdam, and Tinbergen Institute. 
Tinbergen Institute is the graduate school and research institute in economics of Erasmus University Rotterdam, the University of Amsterdam and VU University Amsterdam.

More TI discussion papers can be downloaded at http://www.tinbergen.nl

Tinbergen Institute has two locations:

Tinbergen Institute Amsterdam

Gustav Mahlerplein 117

1082 MS Amsterdam

The Netherlands

Tel.: +31(0)205251600

Tinbergen Institute Rotterdam

Burg. Oudlaan 50

3062 PA Rotterdam

The Netherlands

Tel.: +31(0)10 4088900

Fax: +31(0)104089031

Duisenberg school of finance is a collaboration of the Dutch financial sector and universities, with the ambition to support innovative research and offer top quality academic education in core areas of finance.

DSF research papers can be downloaded at: http://www.dsf.nl/

Duisenberg school of finance

Gustav Mahlerplein 117

1082 MS Amsterdam

The Netherlands

Tel.: +31(0)20 5258579 


\title{
A flexible test for present bias and time preferences using land-lease contracts*
}

\author{
Pieter A. Gautier ${ }^{\dagger}$ Aico van Vuuren ${ }^{\ddagger}$
}

June 9, 2011

\begin{abstract}
When agents have present bias, they discount more between now and the next period than between period $t(>1)$ and $t+1$. How fast the future discount rate (evaluated today) decays is an empirical question. We show that the discount function can be non-parametrically identified with contracts that specify payments that take place at various points in time in the future and which are traded and priced in a competitive market. We use a unique land lease-contract data set for Amsterdam, which has the above properties, to test for present bias in a flexible way. We find no evidence for present bias in this market. Even though we allow for a general-hyperbolic specification (which has exponential discounting as a special case), our estimates converge to an exponential discount function with a corresponding discount rate (in our baseline specification) of $8 \%$.
\end{abstract}

${ }^{*}$ We would like to thank Carla Flemmincks from the for valuable help with the land lease data and the NVM for sharing their housing data with us. We thank conference and seminar participants at various places for useful comments.

†VU University Amsterdam, Tinbergen Insitute and CEPR

${ }^{\ddagger}$ VU University Amsterdam and Tinbergen Institute . 


\section{Introduction}

When agents have present bias, they discount more between now and the next period than between period $t(>1)$ and $t+1$. The notion of present bias goes back to Strotz (1956) and has been applied to a variety of economic settings, see Laibson (1997). Although the existence of present bias in some settings is not controversial, there are still a number of open empirical questions. Those include, under what circumstances is present bias most relevant and to which extent does the discount rate change over time? In this paper we contribute to this literature by using time variation in land lease-payment contracts to estimate present bias in a flexible way. Specifically, we allow for a similar level of flexibility as in the Benhabib et al. (2007).

What sort of data are required to identify present bias? At a given moment in time we need contracts that specify payments that take place at various points in time in the future which are traded and priced today in a market. We use data on land lease in the city of Amsterdam that have this property. Land lease implies that a part of the houses is built on land that is owned by the city of Amsterdam and the home owners must pay land rent for the use of the land. The amount that must be paid, when the payments must be received and how often they must be made, is all specified in land lease contracts. Due to institutional changes and idiosyncratic changes of previous home owners there exists substantial variation in those contracts. To clarify this, suppose we observe two houses, labeled I and II, that have the same predicted value based on neighborhood, size and other characteristics. Suppose further that house I does not have to pay land lease for the next 50 years and is sold for 350,000 in period $t$ while house II must pay 2000 euro per year starting 10 years from now for 50 years and is sold for 300,000 in period $t$. Then, the 50,000 difference in selling price is the market valuation for not having to pay 2000 euro a year, 10 years from now. In our data we observe a variety of contracts with different required payments at different times for different periods which are all priced in the market. This is what allows us to identify the presence of present bias. The structural assumptions that we need to make for identification are that the housing and capital markets function

well, that there are no arbitrage opportunities in equilibrium, that agents have the same time preferences and that they are risk neutral.

Our estimate depends on the expected inflation rate and the expected houseprice growth rate. We assume that the nominal house price changes follow the GDP trend. We find that the Benhabib et al. (2007) specification converges to a standard exponential discount function with a discount rate of $8 \%$. As a robust- 
ness check we also look at higher and lower expected house price changes (the lower bound we use is an expected growth rate of zero) and whether it matters if use a three-step method (hedonics, house price growth, discount function) or estimate our model simultaneously. In most cases we find no evidence for present bias but different specifications do affect the estimated discount rates. However, given previous research in this field, the range is small (between 6 and $11 \%$ ).

Most of the evidence for present bias comes from lab experiments, see Frederick, Loewenstein and O'Donoghue (2002) for an overview. Although some of the evidence they discuss is convincing, we believe that evidence from the field can give important additional information. Our data are interesting because first of all the stakes are a lot higher than what is typically offered in the lab. Housing is the largest investment spending for most people and land lease is a substantial part of that. When the stakes are high, the incentives to invest in information and to calculate (or let an expert calculate) the payoffs over time are large as well. In addition, our population is different than the typical undergraduate population. Finally, experiments can be vulnerable to framing. There are of course also drawbacks of our field data, namely that we have less control over the type of contracts and we must make additional identifying assumptions (all agents have identical discount functions and the housing market is competitive). We therefore view our results as being complementary to the lab evidence.

Warner and Pleeter (2001) also use field data from the military drawdown program data to estimate personal discount rates. This program offered separatees the choice between an annuity and a lump-sum payment. Most of the separatees selected the lump sum, implying a discount rate that exceeds $17 \%$. An advantage of their data is that they have information on individual characteristics and they can identify individual discount rates. Their data does however not allow them to identify present bias whereas with our data this is possible.

The existing papers that identify present bias with field data need to impose more structure than we do. Ahumada and Garegnani (2007) use Argentinean consumption data to estimate a hyperbolic Euler equation and find some evidence for hyperbolic discounting after 2002 but they find exponential discounting before 2002. Fang and Wang (2008) use mammography (screening for breast cancer) decisions and find evidence for both naivety and present bias. Fang and Silverman (2009) estimate a labor supply model on a sample of never-married mothers and allow for time-inconsistent preferences. They estimate the present bias factor to be 0.338 and the standard discount factor to be 0.88 , which implies a one-year discount rate of $238 \%$. Laibson, Repetto and Tobacman (2007) structurally estimate a buffer stock consumption model. Identification comes from the co-movement of 
retirement wealth accumulation, credit-card borrowing and consumption income. Their benchmark estimates imply a $48.5 \%$ short-term annualized discount rate and a 4.3\% long-term annualized discount rate. Paserman (2007) structurally estimates a job search model with hyperbolic discounting and endogenous search effort. Agents in the model face a trade off between current cost (search effort) and future benefits (wages). For low-wage workers, he rejects the exponential discounting model and estimates a one-year discount rate of about $149 \%$. To our knowledge, none of the studies allow for the flexible functional form of Benhabib, Bisin and Schotter (2007) as we do here.

The paper is organized as follows. The next Section introduces the concepts of present bias and hyperbolic discounting. Section 3 describes the land lease system in Amsterdam and our other data sources. Section 4 gives some reduced form results and Section 5 discusses our main test for present bias. Then, in Section 6 we carry out a number of robustness checks and Section 7 concludes.

\section{Present bias and hyperbolic discounting}

Under standard (exponential) discounting, if an agent is indifferent between receiving $100 \$$ now or $105 \$$ next year, she is also indifferent between receiving $100 \$$ in ten years or $105 \$$ in eleven years. When agents have present bias this is no longer the case; preferences are time inconsistent and agents discount more between now and the next period than between $t(>1)$ and $t+1$. The inconsistency arises from the fact that the agent may decide today that she wants to have a certain level of savings at period $t+1$ but once she is in period $t$ she wants to postpone savings again to the future. One implication of this is that it can be rational to voluntarily impose constraints on oneself.

The standard motivation for why agents discount is that future payoffs run some risk of disappearing (see Yaari (1965)). However, if this is the main reason for discounting than hyperbolic discounting requires that this risk becomes smaller over time. Dasgupta and Maskin (2005) give an evolutionary explanation for hyperbolic discounting based on uncertainty about when payoffs are realized. For example, if an agent must choose between a small positive payoff soon (Prospect $P$ ) and a large payoff late $\left(P^{\prime}\right)$ and if there is a small positive probability that both payoffs are realized sooner, this can generate the typical hyperbolic discounting behavior. An agent may initially prefer $P^{\prime}$ but as time evolves switch to $P$ because it becomes more likely that the payoff will not be realized soon.

Villaverde and Mukherji (2006) point out that interpreting the existing ex- 
perimental evidence is difficult because future payments are also more subject to uncertainty. Finally, an alternative way to interpret a lot of the experimental evidence, based on bounded-rationality, is given by Rubinstein (2003).

The (quasi) hyperbolic discount literature replaces the constant discount utility function with a particular alternative form, see Laibson (1997). Benhabib, Bisin and Schotter (2007) propose a more general specification that allows for present bias and also allows for fixed cost. Let $t$ be a point in time and let the discount function, $D(t)$, be given so that an agent is indifferent between an amount of $y D(t)$ today (period 0 ) and $y$ in period $t$. The subjective discount rate is given by

$$
\left|\frac{\partial D(t) / \partial t}{D(t)}\right|
$$

The discount function, $D(t)$ has exponential discounting if,

$$
D(t)=\exp (-\rho t), \rho>0
$$

while it exhibits hyperbolic discounting if

$$
D(t)=\frac{1}{1+\rho t}, \rho>0
$$

and quasi hyperbolic discounting if

$$
D(t)=\left\{\begin{array}{cc}
1 & \text { if } t=0 \\
\alpha \exp (-\rho t) & \text { if } t>0
\end{array} .\right.
$$

Benhabib et al. (2007) propose the following econometric specification that captures all cases, ${ }^{1}$

$$
\begin{aligned}
d(t ; \theta, \rho) & =(1-(1-\theta) \rho t)^{\frac{1}{1-\theta}} \\
D(t) & =\left\{\begin{array}{cc}
1 & \text { if } t=0 \\
\alpha d(t ; \theta, \rho) & \text { if } t>0
\end{array}\right.
\end{aligned}
$$

where the top equation is a generalized parabola and $\theta$ measures the curvature which is hyperbolic for $\theta=2$ and exponential for $\theta=1$. In the lower equation, a quasi hyperbolic bias is present if $\alpha<1$.

There is some evidence that discounting declines with the amount to be discounted, see Benhabib et al. (2007), Thaler (1981), Benzion, Rapaport and Yagil (1989) and Green, Myerson and McFadden. Therefore, researchers have been introducing discount functions which also depend on the amount to be discounted

\footnotetext{
${ }^{1}$ They also allow for a fixed cost from which we abstract here
} 
(see for example Benhabib et al. 2007)). However, these proposed discounting functions are not easy to interpret with contracts where an agent receives or pays a range of quantities in the future. ${ }^{2}$ This is the main reason why we do not allow the discount rate to depend on the size of the payment.

Below, we explain how our data relate to the typical specification that is used to estimate experimental data. Benhabib et al. (2007) assume that the data generating process is as follows. Let $y^{i}(x, t)$ be the answer of subject $i$ to the question: what amount of money $y$ makes you indifferent between $x$ today and $y, t$ days from now where the maximum amount is $y^{l}$ ?

$$
x=y^{i}(x, t) D(t) \varepsilon^{i}(x, t)
$$

and $\varepsilon^{i}(x, t)$ is i.i.d. over subjects. Equation (4) can then be estimated with NLS. In our data we compare approximately identical houses that differ in landlease contracts. Consider two identical houses A and B that are sold in period $t$. House A has a land lease contract (LLC) of $x_{1}$ euro a year for the next 10 years and then $x_{11}$ per year must be paid for the following 50 years while house $\mathrm{B}$ does not have to pay anything for the next 20 years and then $y_{21}$ must be paid for 50 years. The market price difference between house $\mathrm{A}$ and $\mathrm{B}$ reflects time preferences. It is this type of information that we explore to estimate a general discount function. ${ }^{3}$ Finally, we want to emphasize that both in lab and field studies we have to worry that agents can neutralize their actions in the capital market. If capital markets have no imperfections and agents face no commitment problems, monetary amounts at different times can be exchanged without cost at the market interest rate, see also the discussion in Frederick et al. (2002). Suppose for example that a student has a saving account where she gets $5 \%$ interest. Suppose further that she participates in a lab experiment where she has the choice between 100 dollars today and $100+x$ dollar in a year. If $x<5$ she will always prefer the first option even if she has a discount rate below $5 \%$ because at the bank she can transfer 100 dollar today for 105 dollar next year. For a land-lease contract that specifies that after 10 years, $x$ euro a year must be paid, it is potentially possible that the buyer makes an appropriate commitment today

\footnotetext{
${ }^{2}$ In particular, receiving two times $y / 2$ on a particular date would be valued less than $y$ on the same date.

${ }^{3}$ Most of the literature assumes linear preferences (risk neutrality) over money and we do the same here. Although potentially one could deal with concave preferences by estimating

$$
x^{\beta}=y^{\beta} D(t) .
$$
}


and transforms this into one where $y<x$ per year must be paid starting today. In their summary of the literature, Frederick et al. (2002) argue that discount rates can still be identified from choices among tradable rewards if agents ignore opportunities for intertemporal arbitrage in the capital market because of (i) informational or credit frictions or (ii) because they base their choices on other considerations such as time preferences or the uncertainty that comes with delay. Else, the discount rate is only identified if $x>5$ in this example. In our main empirical specification we allow agents to save at the market interest rate. We return to this issue when we discuss identification.

\section{Estimating present bias with land lease data}

\subsection{Land lease}

Land lease is defined as the right to hold and to use someone else's property. For this right the leaseholder must pay the owner an annual fee. This is called the land rent. Land lease is different from tenancy because it can be traded without the intervention of the owner. The city of Amsterdam uses land-lease contracts since 1896. Before that period all land was sold, while after that period the city of Amsterdam always remains the owner of the land. Some houses were property of the city before 1896 and were sold afterwards and the city also frequently buys land belonging to pre-1896 houses. Therefore, there are also land-lease contracts in the older neighborhoods. Houses built after 1896 are always under a land-lease contract unless these houses were built on land that was already sold before 1896 . This implies a non-perfect concentration of houses on own land in the older (and usually more popular) neighborhoods of the city. We take this into account in our empirical analysis.

The duration of a land-lease contract is typically 50 years which we call the

period of lease. At the beginning of the lease period the terms are specified in a contract called the "general conditions" (GC). At present, new contracts are based on the General conditions for perpetual land leases in Amsterdam 2000 (GC2000). However, land-lease contracts with an earlier starting date belong to different GC's. At the date of termination the newest conditions are valid. At the moment, there are contracts that belong to GC's determined in 1915, 1937, 1955, 1966, 1994 and 2000.

An important difference between the recent GC's and those before 1966 concerns the land rent which was mainly a fixed amount before 1966 and is sometimes 
fixed after 1966 and always variable under GC2000. ${ }^{4}$ Another difference between the period before 1966 and the period afterwards is that in the contracts from the earlier periods the land rent period was 75 years while it is only 50 years for the more recent contracts.

At the end of the period of lease, the municipality offers a new contract. ${ }^{5}$ This is determined as follows. The land-lease payments depend on the estimated value of the land. Two years before the period of lease terminates, the municipality sends out a proposal for the value of the land which is estimated by the so called residual method. The land price per square meter is calculated by the residual that remains after subbstracting the estimated construction costs from the estimated market value of the property.

The land-lease owner is allowed to reject the proposal by the municipality. In that case a committee of independent experts is appointed (one member is appointed by the city, one by the leaseholder and one by the other two). As Nelisse (2008) and Veen (2004) show, the offer of the municipality is almost always rejected because it is higher than the experts' evaluation. So for the expected new contracts we can focus on the independent experts who are typically realestate agents. Their procedure is as follows: (1) estimate the total value of the property and multiply this by the land ratio, which is a parameter that usually depends on the neighborhood of the house, and (2) multiply the result with 0.6 in order to take into account that land with property has less value than land without property. ${ }^{6}$ A final aspect of the price determination of the experts is that they try to follow the long-term market trends by determining the total value of the property (in step (1)) instead of the short-term fluctuations of the market. After determining the land price, the (yearly) land rent is simply calculated as a percentage of the land price. ${ }^{7}$

\subsection{Data}

We have data from three different sources. The first source comes from the city of Amsterdam. It contains all the information about land-lease contracts that

\footnotetext{
${ }^{4}$ In the period between 1966 and 2000 different systems were effective from variable to fixed over the period of lease.

${ }^{5}$ In very special cases, the municipality is able to terminate further land rent after the end of the period of lease. In that case the municipality pays the value of the houses. However, these cases happen very rarely and hence we can safely assume in our empirical analysis that leaseholders expect their right to lease the land to last indefinitely.

${ }^{6}$ In practice, the land ratio differs between 0.20 and 0.25 , see Veen (2004) for more details.

${ }^{7}$ The exact percentage depends on the specific contract and on the district within the city.
} 
were effective between 2007 and 2010 with a distinction between those houses for which the land rent is paid in advance and the houses for which the land lease must be paid immediately. In total, we have 158,380 houses for which the land lease is paid in advance. For these houses we have the identifier of the house from the Dutch register, the beginning and the end date of the contract and the beginning and the end date for which the land rent has been paid in advance. Finally, we have information on the general conditions of the land-lease contract, we have the special conditions of the payment period and the exact amount that has to be paid annually during the years of observation. In total there are 56,242 houses for which the land lease was not paid in advance and for which immediate payments must be made.

Our second data set is from the Dutch association of real-estate agents (NVM). It contains at least 70 percent of the total houses sold in Amsterdam over our observation window. The start of the data set is the $1^{\text {st }}$ of January 1985 and the end of the observation window is the $31^{\text {st }}$ of December of 2009 . The total number of sales available is 106346. For every house a large set of characteristics is available based on the information known to the real-estate agent. Among others, we have the address, zip code, the selling price, size (both in square and cubic feet) as well as a large set of features that may have an impact on the price of the house, such as indicators for maintenance (inside and outside the house), period of construction, indicators for the heating system, the situation of the house, the house type, whether there is a garden, balcony, roof terrace or garage attached to the house. We also have an indicator whether the house is under a land-lease contract.

As a third data set we have an official list from the municipality of all houses registered in Amsterdam in 2010. This data set contains the identifier from the Dutch register as well as the address and zip code. We use this data set to match the other two data sets since it contains both the address, zip-code and the registrational code which is used for the land-lease contracts of our first data set.

We merge the second and third data set in order to obtain the identifiers from the registers of all the houses in the second data set. Here, we use street address (with house number and addendum) and zip code. We were able to match 92662 out of the 106346 house sales that appeared in the data from the real-estate association. The main reason we were not able to match all the houses is that the house identifier used by the real-estate agent sometimes is not equal to the house identifier used by the municipality. Especially, the addendum used by the real-estate agent often differs from the addendum used by the municipal- 
ity. Even though we put a lot of effort in matching those houses with different addendums we have been quite conservative in order to minimize the number of wrong matches. Another reason for not being able to match all houses is that some houses sold between 1985 and 2009 do not exist in 2010 and the newly built houses during 2010 did not yet have an official address. We also delete the houses that are not a single unit for the Dutch land register. The problem with these houses is that they do not have a private contract for land lease with the municipality, but instead have a collective contract together with the other houses. Hence, we cannot identify the exact amount of land rent that must be paid by the owner of such a house. This resulted in a deletion of 28464 houses.

Next, we merge the resulting data set with the first data set of all the landlease contracts. Since the land-lease data set contains all contracts, we can define a house to be located on private land if we cannot find a corresponding land-lease contract. There are a few cases where the real-estate agent indicates that the house is not situated on private land. If this occurs, we delete the observation from our data set (about 2 percent). In addition, we merge houses based on the contract that was in place at the moment of the sale. Since we only have information on contracts that were effective over the period 2007 to 2010, some house sales are lost since we do not have any information about the land-lease contract of the house at the moment the house was sold. In total this leaves us with 56587 house sales and after deletion of the houses that do not have all information necessary for estimation (such as size), we keep 49047 observations.

Table 1 below gives some descriptive statistics of our final data set. We make a distinction between private land and land lease. This last category is further subdividided into paid in advance, variable and fixed land lease. Table 1 shows that less than half of the houses are on private land and that the prices of these houses are higher than the prices in any other category. More surprising is the fact that houses with a variable land rent are more expensive than those paid in advance. The most likely reason for this is the fact that those houses are typically sold after 2000. There are not many differences in size between the different categories. However, there are differences between the neighborhoods. For example, own land is overrepresented in the more expensive areas in the city center and the western and southern parts close to the Center. Also for variable land rent, the old Western and Southern parts of the city are overrepresented, while paid in advance and fixed land rent are overrepresented in less popular areas.

For the empirical analysis we divide Amsterdam into 90 different neighborhoods. Those neighborhood definitions are based on Statistics Amsterdam and 
within a neighborhood houses and economic status of the owners are approximately homogenous. Our empirical implementation is based on comparisons within neighborhoods. If some neighborhoods only contain houses on own land or only houses with land lease, then we cannot separately identify a neighborhood and a land-lease effect. Therefore, we deleted all neighborhoods that do not have at least 10 observations from either houses on own land, land lease paid in advance or land rent not paid in advance. This results in a deletion of 53 neighborhoods. Descriptive statistics of the final data set can be found in the lower panel of Table 1.

\section{Results from reduced-form equations}

The first panel of Table 2 lists the results of a regression of price on observed characteristics, neighborhood dummies and the number of years the land rent is paid in advance by the previous owner as well as on a dummy for private ownership of the land (houses which are not paid in advance are excluded). We find, as expected, that a house on own land is more expensive. In addition, we find that the number of years that no land rent has to be paid (because the previous owner paid this in advance) has a significant and positive effect on the house price. In Figure 1 we show the relationship between the spell of time that no land lease has to be paid and the discount on the house price. We have relatively few houses for which the spell of time before the (fixed) contract must be renewed is less than 25 years. This explains the large variance in the beginning.

Next, we turn to houses where the buyer must immediately start to pay land lease. Regressing the house price on the land rent is not a useful exercise if one is interested in the causal effect of land rent on the house price because houses with attractive unobserved characteristics have a higher land rent. However, we do know that there is variation in land rent based on the general conditions of the land-lease contract, while there is not a direct impact on the house price itself. ${ }^{8}$ Therefore, in order to estimate the impact of land rent on the house price, we can use these different general conditions as instruments. The results

\footnotetext{
${ }^{8}$ For example, an important change in the general conditions took place in 1966. As discussed in Section 3.1, before 1966, land lease holders who were offered a new contract paid a fixed land rent and the lease period was typically 75 years. After 1966, the land rent was increased periodically taking the inflation rate into account. Therefore, we expect a large difference in the lease rent between houses for which the land-lease contract was renewed before 1966 and the houses for which it was renewed just after 1966. Since we are looking at the current market, anticipation effects around the date of 1966 are irrelevant.
} 


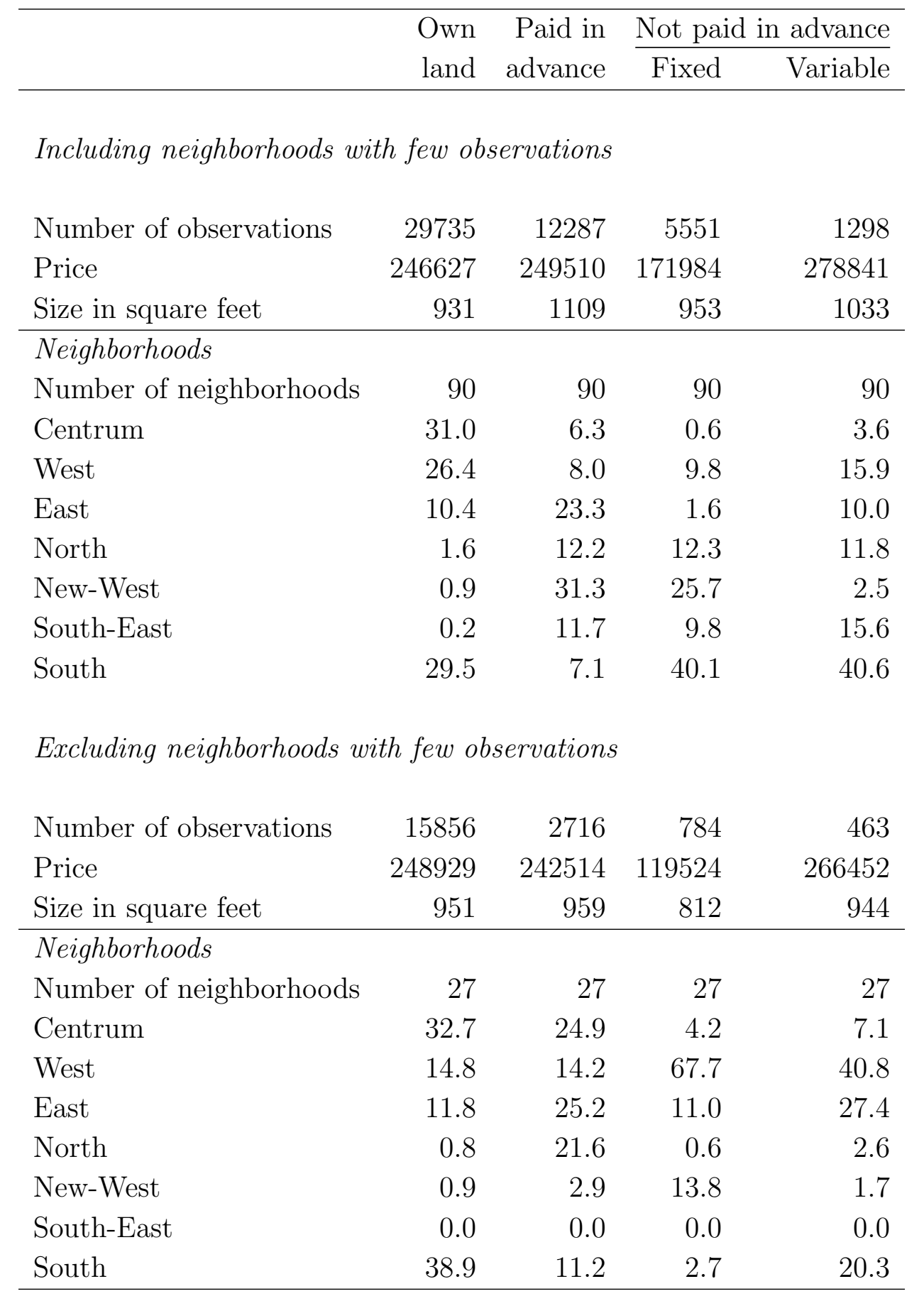

Table 1: Descriptive statistics of the data set. 


\begin{tabular}{cc}
\hline \hline Variable & Estimate \\
\hline \hline
\end{tabular}

Panel 1: regression of price on number of years paid in advance

Private land

Number of years paid in advance (x100)

\section{Panel 2: regression of price on land rent}

Ordinary least squares

Land rent $-0.0132$ $(0.0060)$

Instrumental variable estimation

Land rent

Table 2: Results of reduced form estimates. In all specifications we also correct for size, neighborhoods, squared footage times neighborhood and period of construction, period of construction times neighborhood, year, year times neighborhood, year ${ }^{2}$ times construction, nine categorical dummies for maintenance inside, nine categorical dummies for maintenance outside, dummy for monument, dummy for (partly) let, five categorical dummies for situation, dummy for new house, dummy for investment project, three categorical dummies for heating system, five categorical dummies for isolation. The IV estimates use the general conditions as instruments. 


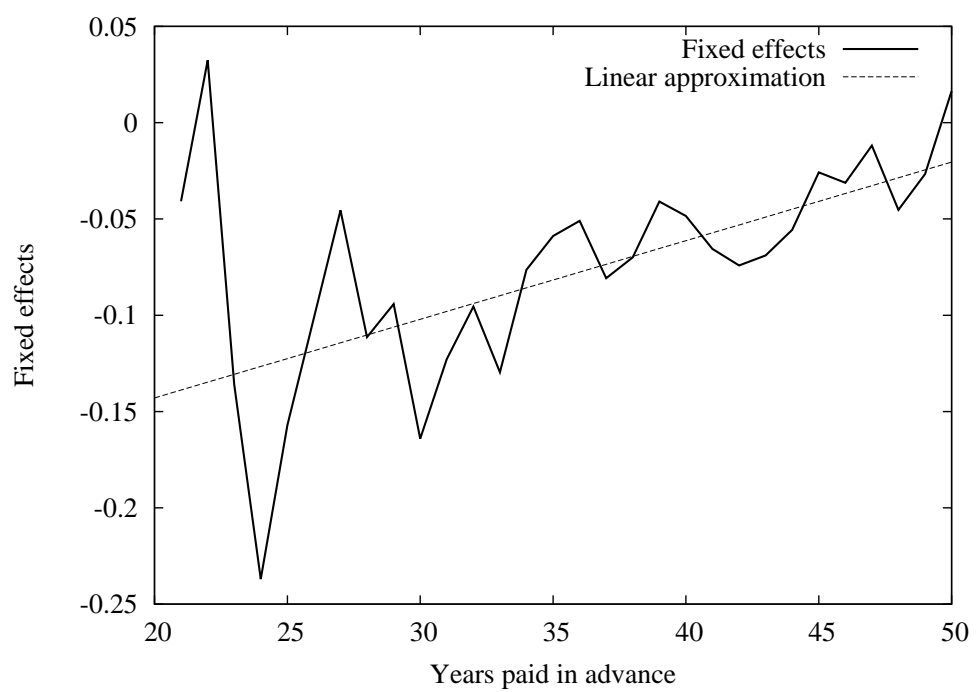

Figure 1: Relationship between house price and the number of years that no land lease has to be paid

of this exercise are in the second panel of Table 2. The upper panel of this table contains estimates of the simple ordinary least squares regressions. As expected, the IV estimates give a stronger negative relation between land lease and house price. We note that our empirical analysis is mainly based on the same idea of taking into account the present conditions of the land lease contract as well as the (expected) future payments. We explain how we take this into account to explore this information to estimate the discount function.

\section{$5 \quad$ Testing for hyperbolic discounting with land lease data}

\section{$5.1 \quad$ Model}

Consider a neighborhood with a large number of identical houses that are sold either on own land or under different land-lease contracts.

Suppose that all buyers can get a mortgage with an interest rate equal to $r$ and that there are no credit constraints up to the value of the house at the moment of buying. In addition, we assume that $D(1)<1 /(1+r) \cdot{ }^{9}$ Let $\widehat{p}_{i}$ be the

\footnotetext{
${ }^{9}$ This implies that there is no reason for individuals to save up to the end of the time horizon. We let the data decide wether this is true.
} 
price of a house on own land. The flow costs of such a house are equal to:

$$
\widehat{p}_{i} \times r \times \sum_{s=1}^{\infty} D(s) .
$$

The owner of a house who leases the land makes additional payments at different points in time. Denote the land rent in period $t$ by $C_{t}$ and the price of such a house by $p_{i}$. The total costs associated with this house equal:

$$
p_{i} \times r \times \sum_{s=1}^{\infty} D(s)+\sum_{s=1}^{\infty} D(s) C_{s}
$$

In a competitive market, buyers must be indifferent between buying a house with private land and with land lease. Therefore, the price of the house without land falls until there is no arbitrage possible implying that (5) and (6) must be equal in equilibrium:

$$
\widehat{p}_{i} \times r \times \sum_{s=1}^{\infty} D(s)=p_{i} \times r \times \sum_{s=1}^{\infty} D(s)+\sum_{s=1}^{\infty} D(s) C_{s} .
$$

Solving for $p_{i}$ gives,

$$
p_{i}=\widehat{p}_{i}-\frac{\sum_{s=1}^{\infty} D(s) C_{s}}{r \times \sum_{s=1}^{\infty} D(s)}=\widehat{p}_{i}-\frac{\sum_{s=1}^{\infty} D(s) C_{s}}{r \times \sum_{s=1}^{\infty} D(s)}
$$

Hence, the price of a house with land lease is equal to the price of that house if it would be located on private land minus the properly discounted costs of the land rent.

Above, we assumed that buyers do not sell their houses. In reality houses are sold frequently (many even within 5 years) so this assumption is violated. However, although the calculus becomes more tedious, our results are not affected as long as drops in house prices can be financed with loans. ${ }^{10}$

\footnotetext{
${ }^{10} \mathrm{In}$ particular, houses for which the land rent is paid in advance are likely to drop in value when the end of the land-lease contract comes in sight. The assumption that this devaluation can be financed by loans is hard to defend since banks are reluctant to refinance previous mortgages whenever the house is sold and when they are willing to do so, they usually require a higher interest rate. However, house prices have actually been increasing at high rates in the past decades. Hence in practice most homeowners do not have to refinance and will only receive less interest payments on their future savings or have to pay higher interest payments on the mortgage of the next house.
} 


\subsection{Identification}

In this subsection we show that a necessary assumption for identification of the model parameters of the previous subsection is that there is variation in the land rents $C_{t}$ over time. If the land rent would be constant in all periods, i.e. $C_{t}=C, t>0$, then,

$$
\widehat{p}_{i}-p_{i}=\frac{C}{r}
$$

and the difference in prices is not informative on the shape of the discount function $D$. This negative result can be explained as follows: when the land rent is constant, a buyer has two options. Either, she buys a house on own land and pays a fixed mortgage payment every period, or she buys a house without the land and she pays a fixed mortgage payment plus the land rent every period. The no-arbitrage condition implies that those payments should be equal and therefore the extra amount that she pays for her mortgage when owning the land (i.e. $\left.\left(\widehat{p}_{i}-p_{i}\right) r\right)$, must be equal to the costs of the land rent. Below, we argue that having variation in $C_{t}$ is not only necessary but in many cases also sufficient for identification of $D$.

To illustrate this, suppose that the seller paid in advance the land lease 30 years ago for 50 years. Then, a new buyer pays nothing for $t_{0}=20$ years and gets a new land rent contract afterwards. Figure 2 illustrates this for a transformation in constant yearly payments. The horizontal line represents the per period costs that a home owner makes for a house on own land (i.e. $\left.\widehat{p}_{i} \times r\right)$ and for a house where the costs are $p_{i} \times r$ for the first 20 periods (only mortgage payments) and $p_{i} \times r+C$ (mortgage plus land rent) afterwards. The no-arbitrage condition implies that in present-value terms, the discounted values for both houses should be equal. In terms of equation (7),

$$
\widehat{p}_{i}-p_{i}\left(t_{0}\right)=\frac{C}{r} \times \frac{\sum_{s=t_{0}+1}^{\infty} D(s)}{\sum_{s=1}^{\infty} D(s)}
$$

If we observe many identical houses with different $t_{0}^{\prime} s$, we can estimate $D(s)$ for $T$ periods. Then, equation (9) generates $T-1$ equations in $D(s), s=1, \ldots T$. This implies that, given $\widehat{p}_{i}, p_{i}\left(t_{0}\right), t_{0}=1, \ldots T-1, C$ and $r, D(s), s=1, \ldots T$, can be non-parametrically identified up to a constant. In reality, not for all houses the land lease is paid in advance. However, in many situations, these houses still have identifying information since the expected land rent payments have some variation. For example, there are houses with a fixed (and usually low) land rent up to the end of the period of lease after which the land rent will be substantially higher. 
Unfortunately, $\alpha$ in equation (3) can only be identified if some payments have to be paid at the moment of buying the house. However, we assume that both the mortgage payments and the land rent is paid at the end of the first year after buying the house. ${ }^{11}$ Therefore, $\alpha$ drops out because it appears proportionally in both the numerator and denominator of (9).

Finally, the fact that we allow agents to save at the market interest rate has an important implication for identification. Suppose an agent considers to buy a house on private land or a house with land lease that must be paid in the future and assume that the interest rate at period 0 exceeds the discount rate. In that case, she can buy the cheaper house (with land lease payments in the future) and start saving for the future payments today. Therefore, the difference in prices between both houses will be driven by the market interest rate and not by the discount function. Hence, if we find the estimated discount rate in the first period to be lower than the interest rate, then we can only identify the upper bound of the discount rate which equals the interest rate in that case. However, if her discount rate at period 0 exceeds the market interest rate, she will not start saving for the future land-rent payments and the house price differences will be driven by the discount function. ${ }^{12}$

\subsection{Empirical implementation}

In our empirical application, $C_{s}$ is not constant and therefore the empirical analysis is more complicated than sketched in the previous section. In addition, not all houses are identical and we do not observe all relevant characteristics. Another practical issue is that we do not know the exact cost of future land-lease contracts so we have to form expectations about them (which are based on the institutional details that we discussed in Section 3.1).

Figure 3 gives a schematic overview of our object of investigation. Time is indicated by $s$ and the year that a particular house is bought is denoted by $t$. Suppose that the number of years since the beginning of the period of lease equals $\tau$ and that the original contract was for $J$ years, so $t-\tau$ is the year in which the last period of lease started. Let $t_{0}=\tau+J-t$ be the number of years until the present period of lease expires. This implies that the current period of lease

\footnotetext{
${ }^{11}$ This assumption does not completely match and it might be possible that in some cases payments are made at the moment of buying the house. Although this would help the identification of $\alpha$, it would really depend on the assumptions about the moments at which payments are made.

${ }^{12}$ Note that this assumes that the maximum amount of the mortgage is determined by the house price. This is the case in the Netherlands.
} 


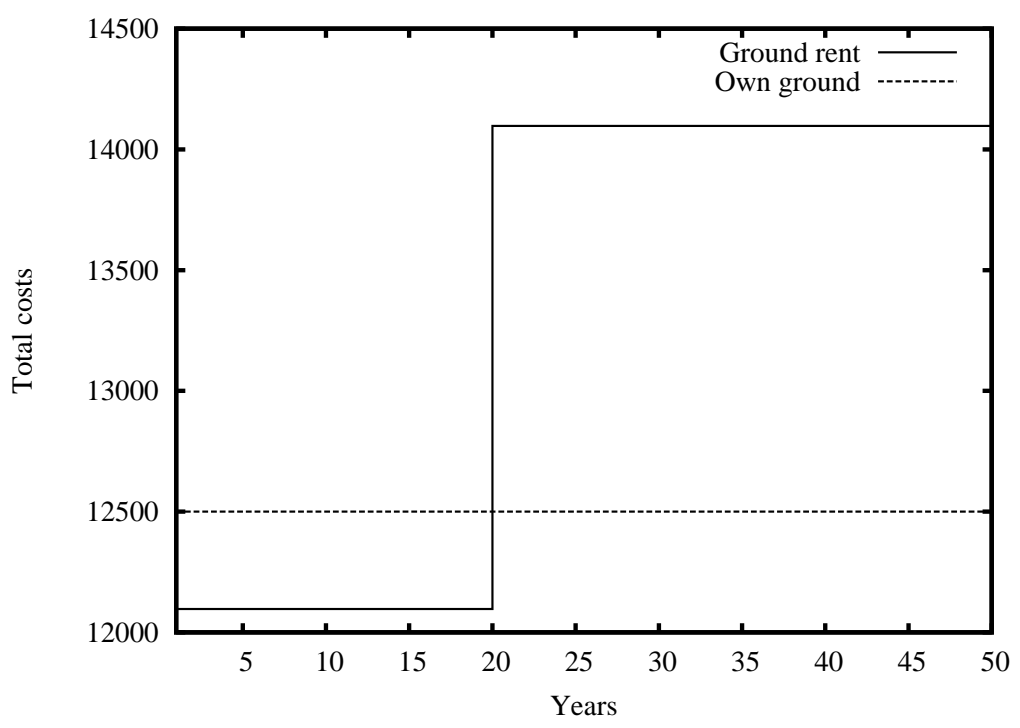

Figure 2: Relationship between house price and the number of years that have been paid in advance

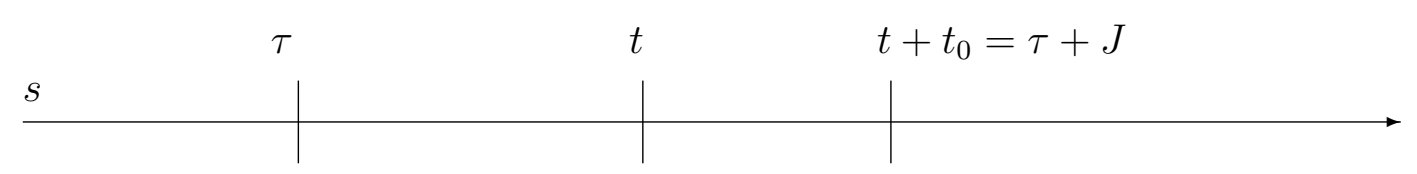

Figure 3: Time line for our empirical implementation

expires at period $t+t_{0}$.

We use $i$ for an observation in the data set and assume that the observations are ordered as follows; first the houses on private land, next the houses for which the land rent is paid in advance and finally we have the houses for which the land rent is not paid in advance. In addition, the number of observations for these three different groups are assumed to be respectively $n_{1}, n_{2}$ and $n_{3}$.

Next, we must make additional identifying assumptions to deal with the fact that houses are not identical. Let $x_{i}$ be the individual characteristics of a house and $\eta_{j}$ a set of dummy variables, which equals one if house $i$ is in region $j$ and zero otherwise. Assume that the price of a house with private land is given by,

$$
\log \widehat{p}_{i}=x_{i} \beta+\eta_{J(i)}+\nu_{i}
$$

Here, $\nu_{i}$ is interpreted as the unobserved characteristics of the house. We make 
the additional assumption that the price of a house that includes the land, changes from our base year, 1985, with a growth rate $\psi_{t}$. Hence, the (log) price of a house $t$ periods from now is: $\log \widehat{p}_{i, t}=\log \widehat{p}_{i}+\sum_{s=1}^{t} \log \left(1+\psi_{s}\right)$. Note that we can estimate $\beta, \eta_{J(i)}$ and $\psi_{s}$ by OLS using the houses that are located on own land (i.e. using observations $1, \ldots n_{1}$ ).

The biggest hurdle we must take is to determine future values of $C_{i, s}$. As we discussed in Section 3.1, the land lease in the periods $\tau$ and $t+t_{0}$ is in practice calculated as a fixed percentage, $\gamma_{i}$, of the value of the house on own land in those periods. We allow $\gamma_{i}$ to be different in different neighborhoods, hence $\gamma_{i}=\gamma_{J(i)}$.

We consider two cases (see Section 3.1): (i) houses for which the lease has been paid in advance for $t_{0}$ years and (ii) houses for which the land lease has not been paid in advance and for which immediate payments must be made. This last case can be further subdivided into fixed and variable land lease.

We start with the first case. For these houses $C_{i, s}=0$ as long as $s<t+t_{0}$. If $s \geq t+t_{0}$ payments must be made. Let $\varphi_{t^{\prime}}$ be the expected land rent increase within a period in year $t^{\prime}$, then

$$
C_{i, s}=\gamma_{J(i)} \exp \left(\sum_{t^{\prime}=1}^{t_{0}} \psi_{t^{\prime}}+\sum_{t^{\prime}=t_{0}}^{s} \varphi_{t^{\prime}}\right) \widehat{p}_{i, t} .
$$

The payments of houses for which the land lease is not paid in advance is also given by equation (11) as long as $s \geq t+t_{0}$. However, it is different when $s<t+t_{0}$. For the fixed case we get,

$$
C_{i, s}=\gamma_{J(i)} \widehat{p}_{i, \tau},
$$

where the house price in period $\tau$ follows from $\widehat{p}_{i, \tau}\left(\sum_{t^{\prime}=\tau}^{t-1} \psi_{t^{\prime}}\right)=\widehat{p}_{i, t}$, while for the variable case it is,

$$
C_{i, s}=\gamma_{J(i)} \widehat{p}_{i, \tau} \exp \left(\sum_{t^{\prime}=\tau}^{t-1} \varphi_{t^{\prime}}\right) .
$$

Combining these two equations, dropping the subscript $s$ (which is always $t$ for the observations) and taking logs gives the following regression equation for houses with a land rent which is not paid in advance (i.e. observations $i=n_{1}+n_{2}+$ $\left.1, \ldots n_{1}+n_{2}+n_{3}\right)$

$$
\log C_{i}-\sum_{t^{\prime}=\tau}^{t-1} \varphi_{t^{\prime}} d_{i}-\log \widehat{p}_{i, \tau}=\log \gamma_{J(i)}+v_{i},
$$

where $d_{i}$ is a dummy variable that equals one for a variable land lease. ${ }^{13}$ This

\footnotetext{
${ }^{13}$ We use the true house price increases for the period after 1985 and before 1985 we use the trend, so $p_{i, \tau}$ follows from, $\left(\sum_{t^{\prime}=\tau}^{1985} \psi+\sum_{t^{\prime}=1985}^{t-1} \psi_{t} \mathbf{1}\left(t^{\prime} \geq \tau\right)\right) p_{i, \tau}=\mathrm{E}\left(p_{i, t}\right)+v_{i}$
} 
makes it possible to estimate $\log \gamma_{J(i)}$ and $\psi_{t}$ (for $t<1985$ ) using OLS. We use the overall price deflator published by Statistics Netherlands, which is also used by the municipality. ${ }^{14}$

Based on these estimates and the equations for $C_{i, s}$ defined above, we can predict the future values of $C_{i, s}$. Substitution of (11) into (7) and replacing $\widehat{p}_{i, \tau}$ by its estimate $\left(\exp \left(-\sum_{s^{\prime}=0}^{t_{0}}\left(\psi_{s^{\prime}}\right)\right) \widehat{p}_{i, t}\right)$ results in an equation for the houses that are paid $t_{0}$ years in advance:

$$
\log p_{i, t}\left(t_{0}\right)=\log \widehat{p}_{i, t}+\log \left(1-\frac{\gamma}{r} \exp \left(\sum_{s^{\prime}=0}^{t_{0}} \psi_{s^{\prime}}\right) \frac{\sum_{s=t_{0}}^{\infty} D(s) \exp \left(\sum_{s^{\prime}=t_{0}}^{s} \varphi_{s}\right)}{\sum_{s=1}^{\infty} D(s)}\right)
$$

Using the approximation $\log (1-x) \approx-x,(10)$ and dropping $t_{0}$ on the left-hand side, we obtain a regression equation for the houses with a land rent that is paid in advance:

$$
\log p_{i}=\mathrm{E} \log \widehat{p}_{i, t}-\frac{\gamma}{r} \exp \left(\sum_{s^{\prime}=0}^{t_{0}} \psi_{s^{\prime}}\right) \frac{\sum_{s=t_{0}}^{\infty} D(s) \exp \left(\sum_{s^{\prime}=t_{0}}^{s} \varphi_{s^{\prime}}\right)}{\sum_{s=1}^{\infty} D(s)}+v_{i}
$$

Similar formulas can be derived for houses that are not paid in advance (see Appendix A for details). From (15) and the formulas derived in the appendix, we can estimate the function $D(s)$ using non-linear least squares.

The final hurdle that we must take is to determine $\varphi_{s^{\prime}}$ and $\psi_{s^{\prime}}$ for $s^{\prime}>0$, i.e. the future values of the inflation rate minus one percent and the rate at which the house prices are going to increase. We assume these values to be constant, which seems to be a valid assumption given the fact that most values for $s^{\prime}$ are far in the future. We assume here that long-run house price changes are equal to the nominal GDP trend. For our baseline analysis we base the trend on the average figures growth rate over the past 25 years. ${ }^{15}$ This gives $\psi=4.23, \phi=0.93$ and $r=5.69$ percent. In our robustness checks we also use average figures over the past 50 years. In that case $\psi=2.54, \phi=5.26$ and $r=6.84$. ${ }^{16}$ The higher $\psi$ the more attractive it is to have a house on own land. This implies that a given price difference between a house on own land and land lease can only be rationalized

\footnotetext{
${ }^{14}$ We test this assumption for the years that we had sequential data of the ground rent(20012009) and find a perfect fit.

${ }^{15}$ We use the Penn World Table to find real GDP increases per capita and we use inflation figures from Statistics Netherlands. Finally, we use nominal interest rates figures from Eurostat.

${ }^{16}$ Note that our estimates are quite close to those found in Eicholtz (1997). He finds a 5.3 percent for the nominal house price increase for the period 1945 to 1973 . If we use housing data for the past 50 years we find a higher value for $\psi$ of $6 \%$ which is mainly due to the explosive price increases in the 90's which we believe are not representative for future house price expectations.
} 
by a relatively large discount rate. As a final robustness check, we set $\psi$ equal to zero to obtain a lower bound on our estimated discount rate.

Note that the main identifying assumption of equation (15) is that $v_{i}$ is independent of $\log \widehat{p}$ (and hence $x$ ) and on the conditions of the land-lease contract (such as fixed, variable land rent and the number of years paid in advance). In words, we assume that the distribution of unobserved characteristics conditional on the observed characteristics is the same between houses with different landlease contracts as well as houses on private land. This assumption is impossible to test, but note that we only consider houses in neighborhoods where all types of land-lease contracts are offered and that have sufficiently many houses on private land.

In our baseline estimates we use a three-step approach to estimate the parameters of the model and we have to take this into account when calculating the standard errors. We describe this in Appendix B.

\subsection{Results}

For each house we can now calculate the amount and timing of future land-lease payments. Our aim is to use those data to flexibly estimate $D(t)$ as defined in equation (3). We estimate four different functional forms of this equation that are common in the literature: (I) exponential, $\theta=1$, (II) hyperbolic, $\theta=2$, (III) general hyperbolic, $\theta \geq 1$. For all these cases we set $\alpha=1$ since as discussed in Section 5.2, we cannot identify $\alpha$ from our empirical analysis. Note that specifications (I) and (II) are special cases of (III).

Our estimation procedure consists of three steps. First, we estimate the hedonics (equation 10), which allows us to calculate the predicted value of each house if it would be located on own land. Then, in the second step, we estimate the expected relationship between house price and land rent $\left(\right.$ i.e. $\gamma_{J 9 i}$ in equation 14). Finally, in the third step we estimate the discount function, given the estimates of step (1) and (2). The advantage of this is that it is transparent, it allows us to see the accuracy of each step and it is simple. As a robustness check, we also estimate the model simultaneously in Section 6. This is less transparent but has some advantages in terms of efficiency. It however does not change our main conclusion that we find no evidence for present bias but it does make the estimated discount rate a bit higher. Finally, we fix the market interest rate at its average value (0.0569). In Section 6, we also estimate the interest rate and we find values that are slightly higher (between 7 and $9 \%$ ).

Table 3 reports the results of the first step of our estimation procedure that 
gives the hedonics. The most important part of this table is the $R^{2}$ value which indicates that we can explain more than 95 percent of the observed variation in house prices by observed characteristics. This is encouraging because it allows us to price the various land-lease contracts (given the observed characteristics of the house). In addition, we find that almost all of the reported coefficients in Table 3 have the right sign and are significant.

Table 4 lists the results of the second step of our estimation method (to get an estimate for $\gamma$ ). The $R^{2}$-value of this step is only 0.4984 with fixed land rent having an $R^{2}$-value equal to 0.4322 and variable land rent having an $R^{2}$-valueequalto0.4116. This is partly due to the fact that it is more difficult to explain the variation in the land-lease payments. However, it is also the result of the relatively small number of regressors we use in this step. Of course, we could have made more regressors dependent on $\gamma$ but as stated above, there is no reason to expect variation between the land-lease payments to be based on other characteristics. ${ }^{17}$ We find that there are remarkable differences between the different neighborhoods. A Hausmann test on joint significance of the neighborhood effects results in a statistic of 797 which strongly rejects the null-hypothesis of no differences between neighborhoods. ${ }^{18}$

Table 5 presents the main results on the discount rate and present bias. The aim is to compare the sum of squared errors for all cases. Our main finding is that the exponential model does much better than the standard-hyperbolic model and that the general hyperbolic specification converges to exponential discounting. So we find no evidence for present bias. The hyperbolic specification implies that myopic behavior gives the best fit of our model but again the performance of this specification is very bad. Finally, we find that the discount rate equals 8 percent which is a reasonable number. Frederick et al. (2002) summarize the empirical literature and report values that range from negative to plus infinity.

Table 6 lists the $R^{2}$-values for different parts of the data set. The exponential specification performs well. With this specification we can explain more than 93 $\%$ of the variance of house prices with land-lease contracts. As, expected from the earlier results the standard-hyperbolic model predicts house prices very poorly.

Another way to look at the performance of our model is to compare the average predicted values with the observed values from the data set. Table 7

\footnotetext{
${ }^{17}$ Including all other characteristics that we also used in the first step of the analysis results in an $R^{2}$-value of 0.639 . However, the standard errors increase a lot making almost all coefficients non-significant.

${ }^{18}$ This statistic follows a $\chi^{2}$-distribution with 27 degrees of freedom under the nullhypothesis).
} 


\begin{tabular}{lr}
\hline \hline Variable & Estimate \\
\hline \hline & \\
Log squared footage $(\times 100)$ & 0.5569 \\
& $(0.0201)$ \\
Log cubic footage $(\times 1 \mathrm{mln})$ & 0.1451 \\
& $(0.0069)$ \\
Number of rooms & 0.0173 \\
& $(0.0013)$ \\
Monument & 0.0456 \\
& $(0.0054)$ \\
Garden & 0.0386 \\
& $(0.0037)$ \\
Garage & 0.0240 \\
Luxurious & $(0.0024)$ \\
\# of balconies & 0.0350 \\
Roof terrace & $0.0038)$ \\
Congested road & 0.0116 \\
& $(0.0027)$ \\
Basement & 0.0391 \\
& $(0.0042)$ \\
\# of bathrooms & -0.0412 \\
Ground surface $(\times 100)$ & 0.0061 \\
$R^{2}$ & 0.0131 \\
Number of observations & $(0.0089)$ \\
\hline \hline
\end{tabular}

Table 3: Estimates of the first stage regression of log house prices of houses on own land on house characteristics. We also correct for neighborhoods, squared footage times neighborhood and period of construction, period of construction times neighborhood, year, year times neighborhood, year ${ }^{2}$ times construction, nine categorical dummies for maintenance inside, nine categorical dummies for maintenance outside, dummy for monument, dummy for (partly) let, five categorical dummies for situation, dummy for new house, dummy for investment project, three categorical dummies for heating system, five categorical dummies for isolation 


\begin{tabular}{lrlr}
\hline \hline Variable & Estimate & Variable & Estimate \\
\hline \hline Grachtengordel-Zuid & 0.9456 & Stadionbuurt & -1.4564 \\
& $(0.4296)$ & & $(0.2798)$ \\
Nieuwmarkt/Lastage & -0.7077 & IJselbuurt & -0.9329 \\
& $(0.3891)$ & & $(0.2931)$ \\
Diamantbuurt & -0.0127 & Rijnbuurt & -1.074 \\
& $(0.2189)$ & & $(0.2806)$ \\
Transvaalbuurt & -1.5348 & Frankendael & -0.1274 \\
& $(0.2961)$ & & $(0.2879)$ \\
Indische buurt oost & -1.3166 & Middenmeer & -1.1081 \\
& $(0.2835)$ & & $(0.2806)$ \\
Landlust & -0.8673 & Volewijck & -1.3202 \\
& $(0.2792)$ & & $(0.3250)$ \\
Erasmuspark & -1.2310 & Oostzanerwerf & 0.7359 \\
& $(0.2817)$ & & $(0.3392)$ \\
De Kromert & -0.9882 & Nieuwedam Noord & -0.1202 \\
& $(0.2861)$ & & $(0.2800)$ \\
Van Galenbuurt & -1.2952 & Slotermeer Zuidwest & -0.9011 \\
& $(0.2901)$ & & $(0.2792)$ \\
Hoofdweg e.o. & -2.2027 & Osdorp Midden & -0.4988 \\
& $(0.2861)$ & & $(0.2811)$ \\
Hoofdorppleinbuurt & -1.0003 & Sloter-/riekpolder & -0.1036 \\
& $(0.2890)$ & & $(0.3004)$ \\
Willemspark & -0.2578 & Buitenveldert west & -0.5128 \\
& $(0.3004)$ & & $(0.2777)$ \\
Museumkwartier & -0.5129 & & -0.0149 \\
$R^{2}$ & $(0.2992)$ & & $(0.0010)$ \\
\hline \hline & & Constant & -4.8435 \\
& 0.5462 & Number of observations & $(0.3633)$ \\
& & & 3145 \\
\hline
\end{tabular}

Table 4: Results of the second stage regression of the log land rent on neighborhood and the number of years since start of land rent. 


\begin{tabular}{ccc}
\hline \hline Exponential & $\begin{array}{c}\text { Standard } \\
\text { hyperbolic }\end{array}$ & $\begin{array}{c}\text { General } \\
\text { hyperbolic }\end{array}$ \\
\hline \hline
\end{tabular}

\section{Basic model parameters}

\begin{tabular}{lrrr}
$\rho$ & 0.0820 & $\infty$ & 0.0820 \\
$\theta$ & $(0.0099)$ & $(\cdot)$ & $(0.0099)$ \\
& 1.000 & 2.000 & 1.000 \\
& & & $(\cdot)$ \\
Sum of squared residuals & 93.80 & 57329 & 93.80 \\
& & & \\
\hline \hline
\end{tabular}

Table 5: Baseline results of the model estimates.

\begin{tabular}{lccc}
\hline \hline & Exponential & $\begin{array}{r}\text { Standard } \\
\text { hyperbolic }\end{array}$ & $\begin{array}{c}\text { General } \\
\text { hyperbolic }\end{array}$ \\
\hline \hline & 0.9330 & -37.19 & 0.9330 \\
Overall & & & \\
Paid by previous owner & 0.8247 & -133.05 & 0.8247 \\
Fixed land rent & 0.9673 & -3.6064 & 0.9673 \\
Variable land rent & 0.9029 & -17.09 & 0.9029 \\
& & & \\
\hline \hline
\end{tabular}

Table 6: $\mathrm{R}^{2}$ values for the different parts of the dataset 


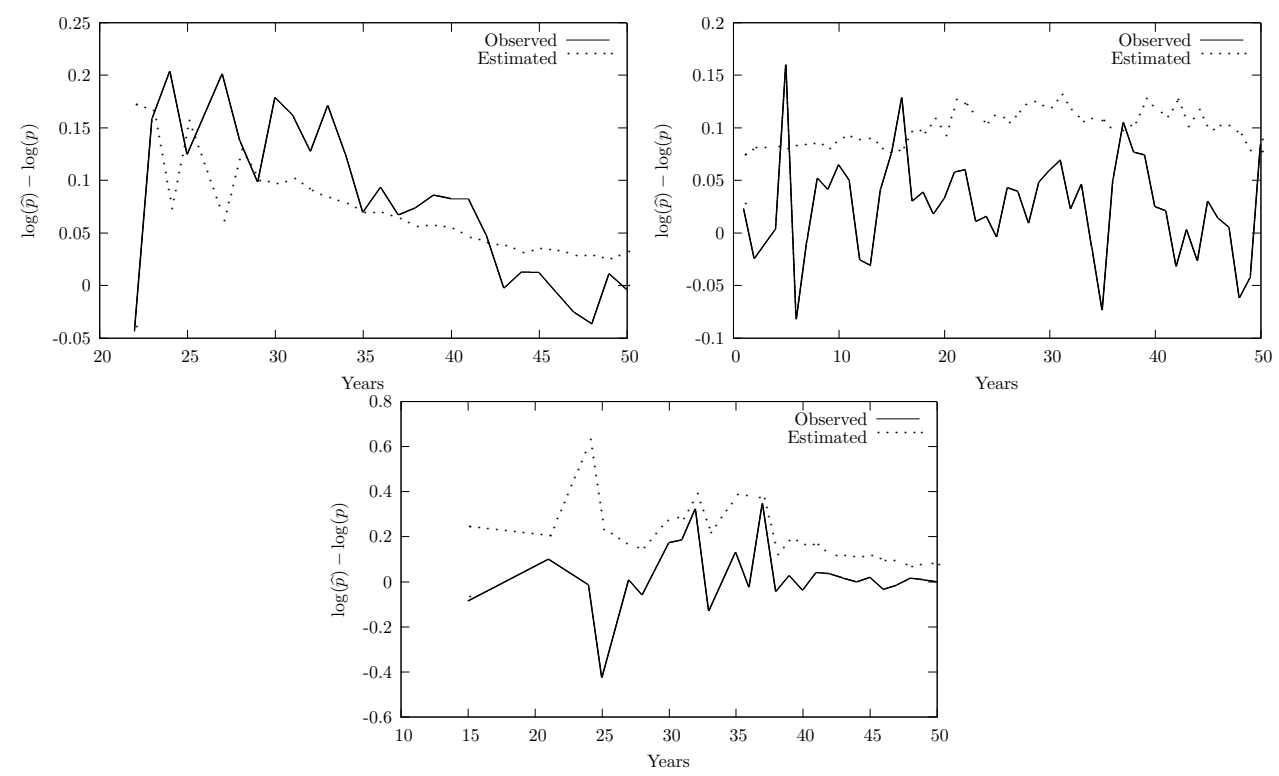

Figure 4: Relationship between house price and the number of years that have been paid in advance

lists the results from this exercise. For all the different types of houses (i.e. private land, paid by previous owner, fixed and variable land rent) we report the observed values, the estimated values and the estimated values on private land. Not surprisingly, these are all the same for the private land group. In addition, as expected, the average value of house prices on private land exceeds the average observed value for the other categories. The estimated values of the model (i.e. the second column) should be as close as possible to the observed averages. We find small differences for the exponential model where the estimated value slightly overpredictings the average price of a house which is paid in advance while it slightly underpredicts the average price of the other two categories. Again, the standard hyperbolic performs very poor.

Figure 4 looks at the fit over the years. The first panel is for houses where the land lease was paid by the previous owner, the second one for fixed land rent and the last one for variable land rent.

\section{Robustness checks}

In this section, we present robustness checks on some of the assumptions we made in the previous section. First, in section 6.1 we estimate the interest rate rather than use calibrated values. Then in section 6.2 we estimate all three 


\begin{tabular}{lrr}
\hline \hline Observed & $\begin{array}{r}\text { Prices } \\
\text { Predicted }\end{array}$ & $\begin{array}{r}\text { Predicted on } \\
\text { own land }\end{array}$ \\
\hline \hline
\end{tabular}

\section{Exponential}

Land rent

$\begin{array}{llll}\text { Paid by previous owner } & 12.305 & 12.307 & 12.347 \\ \text { Fixed land rent } & 11.425 & 11.404 & 11.453 \\ \text { Variable land rent } & 12.352 & 12.314 & 12.379\end{array}$

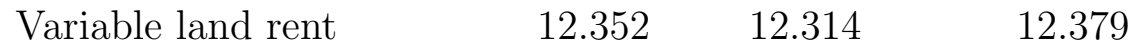

\section{Standard Hyperbolic}

Land rent

Paid by previous owner

$\begin{array}{lll}12.305 & 8.7629 & 12.347 \\ 11.425 & 10.097 & 11.453 \\ 12.352 & 10.812 & 12.379\end{array}$

Variable land rent

$12.352 \quad 10.812$

12.379

\section{General hyperbolic}

Land rent

$\begin{array}{llll}\text { Paid by previous owner } & 12.305 & 12.307 & 12.347\end{array}$

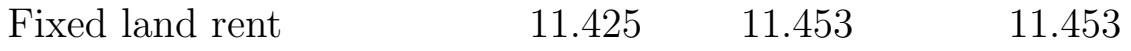

$\begin{array}{llll}\text { Variable land rent } & 12.351 & 12.314 & 12.379\end{array}$

Table 7: Average (predicted) values for the different parts of the dataset (using $\operatorname{logs})$ 
steps simultaneously rather than in three steps. Section 6.3 gives the estimation results excluding the variable land-lease contracts and finally in section 6.4, we use different values for the expected inflation rate and the house price trend. The bottom line is that our main results are robust. The hyperbolic specification always performs bad. Only in the case where we estimate the interest rate, we find some evidence for present bias; $\theta$ is 1.1 rather than 1 . However, even in that case, the SSR is almost the same as in the nested exponential case. In all other cases we find that the general hyperbolic converges to the exponential. If house prices are expected not to increase over time, the estimated discount rate is about $1 \%$. In all other cases, with different inflation rates and different GDP trends, we find the estimated discount rate to be in the order of 6-10\%.

\subsection{The interest rate}

For our baseline analysis we set the level of the interest rate equal to the interest rate over the past 25 years. However, even in the exponential case the interest rate is identified and can be estimated. Table 8 lists the results of this exercise. In general, we find that the interest rate is estimated to be larger than the discount rate in the first period and, as discussed at the end of Section 5.2, in that case we can only estimate an upper bound of the discount rate. In addition, we find the estimated interest rates to be a bit higher than the interest rate over the past 25 and 50 years. Since for the market participants the expected interest rate is relevant, we prefer the baseline analysis. Nevertheless, it is a good sign that the estimated interest rates are of the same order of magnitude as the observed ones. Table 8 indicates that the general hyperbolic model does slightly better than the exponential model. Although this can be a sign that there is indeed some present bias, we should be careful here. Note that the discount rate in the first period (i.e. $\rho$ ) should be interpreted here as an upper bound and the discount function can only be identified if we assume that $\rho$ exactly equals its upper bound. We also see that the performance of the exponential specification in terms of SSR is almost as good as the general hyperbolic.

\subsection{Simultaneous estimation of the three stages}

In our baseline analysis, we estimate our model in a three-stage estimation procedure. It is also possible to estimate all the three steps simultaneously. The results of this exercise are summarized in Table 9 . We find a bit higher discount rates than in our baseline analysis, but still there does not seem to be any support for the presence of present bias. The simultaneous estimation procedure has a 


\begin{tabular}{ccc}
\hline \hline Exponential & $\begin{array}{c}\text { Standard } \\
\text { hyperbolic }\end{array}$ & $\begin{array}{c}\text { General } \\
\text { hyperbolic }\end{array}$ \\
\hline \hline
\end{tabular}

\section{Basic model parameters}

\begin{tabular}{lrrr}
$\rho$ & 0.0739 & $\infty$ & 0.0925 \\
$\theta$ & $(\cdot)$ & $(\cdot)$ & $(\cdot)$ \\
& 1.000 & 2.000 & 1.1058 \\
$r$ & & & $(0.1068)$ \\
& 0.0739 & $\infty$ & 0.0925 \\
Sum of squared residuals & $(0.0012)$ & $(\cdot)$ & $(0.0231)$ \\
& & & \\
& & & \\
\hline \hline
\end{tabular}

Table 8: Results based on estimated interest rates

somewhat better fit than our three step estimation procedure. This follows from Table 9 that reports the sum of sqaured residuals (note that the overall sum of squared residuals is higher than in the previous tables since it also includes the sum of squared residuals of equations (10) and (14)).

If the distribution of the unobserved characteristics of all houses, conditional on the observed characteristics, is not the same for houses with different landlease contracts, the regression coefficients of the first step and second step in our three-step method will be (significantly) different from the estimates we obtain in our simultaneous procedure. A test on whether the estimates of $\beta$ from equation (10) are significantly different for the two estimation methods results in a test statistic equal to 268. Under the null-hypothesis of no difference between the estimated $\beta$ 's from the two estimation methods, this test-statistic follows a $\chi^{2}$ distribution with 215 degrees of freedom. This implies that the null-hypothesis is not rejected. For the difference with the second step estimator we obtain a test statistic equal to 2.6 and this statistic follows a $\chi^{2}$ distribution with 27 degrees of freedom under the null. Hence, also this test is not rejected. If we take all three steps together we obtain a test statistic which is equal to 280 and this statistic has 242 degrees of freedom. This implies that there is no evidence that our model is misspecified by estimating the fact that the unobserved characteristics of the houses on private land are different from the unobserved characteristics of the houses with a land-lease contract. 


\section{Basic model parameters}

$\begin{array}{lrrr}\rho & 0.1133 & \infty & 0.1133 \\ \theta & (0.0176) & (\cdot) & (0.0176) \\ & 1.000 & 2.000 & 1.000 \\ & & & (0.4075) \\ \text { Sum of squared residuals } & 743.77 & 1431 & 743.63 \\ \text { Sum of squared residuals for the last step } & 54.44 & 306.4 & 54.44\end{array}$

Table 9: Results based on simultaneous estimation of the three seperate equations

\subsection{Estimation excluding the variable land-lease contracts}

One potential concern is that individuals who buy houses with variable land-lease contracts are very different from the other buyers. To see whether those contracts are very different from the others we also estimate our model without those contracts, see Table 10 for the estimation results. Again, this does not change any of our conclusions. The general hyperbolic converges to the exponential discount function and the estimated discount rate is now 7.8 rather than $8.0 \%$.

\subsection{Estimation with different calibrated parameters}

Table 11 lists the results when we change the calibrated model parameters, $\phi$ (inflation minus one) and the growth rate of house prices that we estimated from the real GDP trend of the past 25 years but that could also be estimated from the past 50 years (which gives a lower rate, 1.7 instead of $2.3 \%$ ). As a lower bound we consider a growth rate of $0 \%$. Finally, we varied the expected market interest rate. In all cases, our estimated discount rate remains in a reasonable range, between 6 and $10 \%$.

\section{Final remarks}

When agents have present bias, they discount more between now and the next period than between period $t(>1)$ and $t+1$. How fast the future's discount rate 


\begin{tabular}{ccc}
\hline \hline Exponential & $\begin{array}{c}\text { Standard } \\
\text { hyperbolic }\end{array}$ & $\begin{array}{c}\text { General } \\
\text { hyperbolic }\end{array}$ \\
\hline \hline
\end{tabular}

Basic model parameters

$\begin{array}{rrrr}\rho & 0.0780 & \infty & 0.0780 \\ \theta & (0.0049) & (\cdot) & (0.0049) \\ 1.000 & 2.000 & 1.000 \\ & & & (0.4075)\end{array}$

$\begin{array}{llll}\text { Sum of squared residuals } & 83.35 & 36342 & 83.35\end{array}$

Table 10: Results excluding observations of variable land rent.

\begin{tabular}{lllr}
\hline \hline & \multicolumn{3}{c}{ Growth rate } \\
\cline { 2 - 4 } & 0 & 0.0172 & 0.023 \\
\hline \multicolumn{4}{c}{ Interest rate $=0.0569$} \\
$\phi=0$ & 0.0569 & 0.0608 & 0.0668 \\
$\phi=0.0093$ & 0.0578 & 0.0743 & $\mathbf{0 . 0 7 9 9}$ \\
$\phi=0.0254$ & 0.0807 & 0.0961 & 0.1014 \\
& & & \\
Interest rate $=0.0684$ & \\
$\phi=0$ & & & \\
$\phi=0.0093$ & 0.0684 & 0.0693 & 0.0750 \\
$\phi=0.0254$ & 0.0759 & 0.0911 & 0.0964 \\
\hline \hline
\end{tabular}

Table 11: Results of the estimated discount rate when we change the calibrated model parameters 
evaluated today decays is an empirical question. In this paper, we showed that the discount function can be non-parametrically identified using contracts that specify payments that take place at various points in time in the future and which are traded and priced in a market. We then use land lease data from Amsterdam which have this characteristic to test for present bias in a flexible way. We find no evidence for present bias in this market. With the data we have, we can however not rule out that agents discount a lot between today and a week or a month from now and from then onwards, have a constant discount rate. We can show that particular functional forms that have been proposed, like the hyperbolic, give a bad fit. The general hyperbolic specification that has the exponential discount function as a special case, converges to the exponential. The estimated discount rate falls in the range between 6 and $10 \%$. Compared to many of the previous studies (that find values ranging from negative to plus infinity), those values are in the reasonable range. 


\section{References}

Ahumada, H.A. And M.L. Garegnani (2007), "Testing hyperbolic discounting in consumer decisions: Evidence for Argentina", Economics Letters, 95, $146-150$.

Benhabib, J., A. Bisin And A. Schotter (2007), "Present-bias, quasihyperbolic discounting, and fixed costs", working paper, New York University.

Benzion, U., A. Rapoport and J. Yagil (1989), "Discount Rates Inferred from Decisions: An experimental study ", Management Science 35, 270 284.

Dasgupta, P. And E. Maskin (2005), "Uncertainty and Hyperbolic Discounting ", American Economic Review, 95, 1290-1299.

Eichholtz, P.M.A. (1997), "A Long Run House Price Index: The Herengracht Index, 1628-1973". Real Estate Economics, 25, 175-92.

Fang, H. And D. Silverman (2009), "Time-inconsistency and welfare program participation, evidence from the NLSY, International Economic Review, 50, 1043-1077.

FAng, H. And Y. WAng (2008), "Estimating Dynamic Discrete Choice Models with Hyperbolic Discounting, with an Application to Mammography Decision", Working paper, Duke University, Durnham.

Fernández-Villaverde, J. And A. Mukherji (2006), "Can We Really Observe Hyperbolic Discounting?", working paper, University of Pennsylvenia, Philladelphia.

Frederick, S., G. Loewenstein, and T. O'Donoghue (2002), "Time discounting and time preference: a critical review", Journal of Economic Literature 150, 351-401.

Green L., J. Myerson And E. McFadden (1997). "Rate of temporal discounting decreases with amount of reward", Memory and Cognition 25, $715-723$.

LAIBSON, D. (1997), "Golden eggs and hyperbolic discounting", Quaterly Journal of Economics 112, 443-477.

Laibson, D., A. Repetto And J. Tobacman, (2007), "Estimating discount 
functions with consumption choices over the lifecycle", working paper, Harvard University, Cambridge.

Paserman, D. (2008), "Job search and hyperbolic discounting: structural estimation and policy evaluation", Economic Journal, 118, 1418-1452.

Rubinstein, A. (2003), "Economics and psychology'? The case of hyperbolic discounting ", International Economic Review, 44, 1207-1216.

Thaler, R. (1981), "Some empirical evidence on dynamic inconsistency", Economics Letters 8, 201-207.

VeEn, I. (2004), "De waarde van een erfpachtrecht in het Amsterdamse stelsel, in het bijzonder van voortdurende rechten bij canonherziening einde tijdvak.", Working paper, Amsterdam.

Warner, J.T. And S. Pleeter (2001), The American Economic Review, Vol. 91, No. 1, 33-53.

YAARI, M.E. (1965), "Uncertain lifetime, life insurance, and the theory of the consumer ", Review of Economic Studies 32, 137-150.

\section{Appendix}

\section{A Deriving the relation between house prices, land lease payments and the discount rate}

Similarly to equation (15), we substitute (11) and (12) into (7) and replace $\widehat{p}_{i, \tau}$ by its estimate and use again the approximation $\log (1-x) \approx-x$, we obtain an expression for the fixed land rent

$\log p_{i}=\mathrm{E} \log \widehat{p}_{i}-\frac{\gamma}{r} \frac{\sum_{s=1}^{t} \exp \left(-\sum_{t^{\prime}=\tau}^{t-1} \psi_{t^{\prime}}\right) D(s)+\exp \left(\sum_{s^{\prime}=0}^{t_{0}} \psi_{s^{\prime}}\right) \sum_{s=t_{0}}^{\infty} D(s) \exp \left(\sum_{s^{\prime}=t_{0}}^{s} \varphi_{s^{\prime}}\right)}{\sum_{s=1}^{\infty} D(s)}+v_{i}$.

For the variable land-rent case we can use equation (13) instead of equation (12) to substitute into equation (7) and use the same steps as above to obtain:

$\log p_{i}=\mathrm{E} \log \widehat{p}_{i}-\frac{\gamma}{r} \frac{\sum_{s=1}^{t} \exp \left(\sum_{t^{\prime}=\tau}^{t-1}\left(\phi_{t^{\prime}}-\psi_{t^{\prime}}\right)\right) D(s)+\exp \left(\sum_{s^{\prime}=0}^{t_{0}} \psi_{s^{\prime}}\right) \sum_{s=t_{0}}^{\infty} D(s) \exp \left(\sum_{s^{\prime}=t_{0}}^{s} \varphi_{s^{\prime}}\right)}{\sum_{s=1}^{\infty} D(s)}+v_{i}$

\section{B Derivation of the asymptotic standard errors}

We use the following notation for equation (10),

$$
\log \widehat{p}_{i}=x_{i} \beta+\eta_{J(i)}+\nu_{i}=y_{i} B+\nu_{i}, \quad i=1, \ldots n_{1},
$$


and for equation (14) we use

$$
\log C_{i}=x_{i} \beta+\sum_{t^{\prime}=\tau}^{t-1} \psi_{t^{\prime}} d_{i}+\log \gamma_{J(i)}+\nu_{i}=z_{i} \delta+\nu_{i}, \quad i=n_{2}, \ldots, n_{3} .
$$

As in the paper, we estimate first $B$ with OLS and then substitute this into the secondstage regression to estimate $\delta$. It implies that

$$
\left(\begin{array}{c}
y^{T}(\log \widehat{p}-y \widehat{B}) \\
z^{T}(\log C-y \widehat{B}-z \delta)
\end{array}\right)=\left(\begin{array}{l}
0 \\
0
\end{array}\right)
$$

where $y$ and $z(\log \widehat{p}$ and $\log C)$ without a subscript for the observation implies that these are matrices (vectors) of all the observations. Then using a Taylor series expansion for $\widehat{B}$ and $\widehat{\delta}$ around the true values and using the central limit theorem we can prove that,

$$
\left(\begin{array}{c}
\sqrt{n_{1}}(\widehat{B}-B) \\
\sqrt{n_{3}}(\widehat{\delta}-\delta)
\end{array}\right) \rightsquigarrow N(0, \Omega)
$$

where,

$$
\Omega=\left(\begin{array}{cc}
n_{1} \Sigma_{1} & -n_{1} \Sigma_{1} z^{T} y\left(z^{T} z\right)^{-1} \\
-n_{1}\left(z^{T} z\right)^{-1}\left(y^{T} y\right) \Sigma_{1} & \frac{n_{3}^{2}}{n_{1}}\left(z^{T} z\right)^{-1} y^{T} z \Sigma_{1} z^{T} y\left(z^{T} z\right)^{-1}+n_{3} \Sigma_{2}
\end{array}\right),
$$

and

$$
\Sigma_{1}=\left(y^{T} y\right)^{-1} \sigma_{\nu}^{2} \quad \Sigma_{2}=\left(Z^{T} Z\right)^{-1} \sigma_{\nu}^{2} .
$$

Substitution of $\widehat{B}$ and $\widehat{\delta}$ results in the third-stage regression,

$$
\log p_{i}=y_{i} \widehat{B}+g_{i}(\rho, \widehat{B}, \widehat{\delta})+\nu_{i},
$$

for $i=n_{1}+1, \ldots n_{1}+n_{2}+n_{3}$ and where the coefficient of interest is $\rho$. The function $g_{i}$ directly follows from (15) and the two equations from Appendix A. Then,

$$
\frac{1}{\sqrt{n_{2}+n_{3}}} \sum_{k=1}^{n_{2}+n 3} \nu_{i} \frac{\partial g(\widehat{\rho}, \widehat{B}, \widehat{\delta})}{\partial \rho}=0
$$

Taking a Taylor-series expansion of $\widehat{\rho}$ around $\rho$ and then taking a Taylor-series expansion of $\widehat{B}$ and $\widehat{\delta}$ around $B$ and $\delta$, we obtain

$$
\begin{aligned}
0 & =\frac{1}{\sqrt{n_{2}+n_{3}}} \sum_{k=1}^{n_{2}+n_{3}} \nu_{i} \frac{\partial g(\rho, B, \delta)}{\partial \rho}+\frac{1}{n_{2}+n_{3}} \frac{\partial}{\partial \rho} \sum_{k=1}^{n_{2}+n_{3}} \nu_{i} \frac{\partial g(\rho, B, \delta)}{\partial \rho} \sqrt{n_{2}+n_{3}}(\widehat{\rho}-\rho) \\
& +M_{1} \times\left(\begin{array}{c}
\sqrt{n_{1}}\left(\widehat{B^{T}}-B\right) \\
\sqrt{n_{3}}(\widehat{\delta}-\delta)
\end{array}\right)+o_{p}(1),
\end{aligned}
$$


where

$$
\widehat{M}_{1}=\left(\frac{1}{n_{2}+n_{3}} \sqrt{\frac{n_{2}+n_{3}}{n_{3}}} \frac{\partial}{\partial B} \sum_{k=1}^{n_{2}+n_{3}} \nu_{i} \frac{\partial g(\rho, B, \delta)}{\partial \rho} \quad \frac{1}{n_{2}+n 3} \sqrt{\frac{n_{2}+n_{3}}{n_{1}}} \frac{\partial}{\partial \delta^{T}} \sum_{k=1}^{n_{2}+n_{3}} \nu_{i} \frac{\partial g(\rho, B, \delta)}{\partial \rho}\right) .
$$

Based on the results above, the final part converges to a normal distribution with mean zero and covariance matrix $M_{1} \Omega M_{1}$, where $M_{1}$ equals $\widehat{M}_{1}$ but with mean signs instead of the summation over the observations. Using the central limit theorem, the first part also converges to a normal distribution with mean zero and the covariance matrix is the score matrix.

$$
H_{0}=\mathrm{E}\left(\frac{\partial g(\rho, B, \delta)}{\partial \rho} \frac{\partial g(\rho, \beta, \delta)}{\partial \rho^{T}} \nu^{2}\right)
$$

Define,

$$
M_{0}=\mathrm{E}\left(\frac{\partial^{2} g(\rho, B, \delta)}{\partial \rho \partial \rho^{T}} \nu_{i}\right) .
$$

By the law of large numbers the matrix in front of the second term of equation (18) converges to this matrix $M_{0}$. Then substitution of all these results into equation (18) and rewriting terms results in,

$$
\sqrt{N}(\widehat{\rho}-\rho) \rightsquigarrow N\left(0, M_{0}^{-1}\left(H_{0}+M_{1} \Omega M_{1}\right) M_{0}^{-1}\right) .
$$

